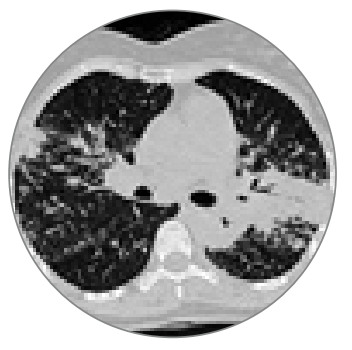

$\boldsymbol{1}$

\section{Palabras clave (DeCS) \\ Tomografía \\ computarizada \\ multidetector \\ Radiografía torácica \\ Sarcoidosis \\ Sarcoidosis pulmonar}

\section{Key words (MeSH)}

Multidetector computed

tomography

Radiography, thoracic

Sarcoidosis

Sarcoidosis, pulmonary
Médico, Sección de Tomografía Computarizada, Country Scan LTDA. Departamento de Radiología, Hospital Universitario San Ignacio, Pontificia Universidad Javeriana. Bogotá, Colombia. ORCID: https://orcid.org/00000002-3093-2509

2Médica general, Universidad del Rosario. Bogotá, Colombia. ORCID: https://orcid. org/0000-0001-6773-7064

${ }^{3}$ Médico, Departamento de Radiología, Unidad PET-CT, Clínica del Country. Departamento de Radiología, Hospital Universitario San Ignacio, Pontificia Universidad Javeriana. Bogotá, Colombia. ORCID: https://orcid.org/0000oo03-1329-8769

\title{
Compromiso torácico de la sarcoidosis en tomografía computarizada: claves clínicas y radiológicas
}

\author{
Thoracic Involvement of Sarcoidosis in Computed Tomography: \\ Radiological Manifestations and Key Findings
}

Felipe Aluja Jaramillo

Alejandra Mendoza Guerra²

Alfonso Lozada Medellín ${ }^{3}$

\section{Resumen}

La sarcoidosis es una enfermedad crónica y multisistémica de etiología poco clara. La presentación es variable, de acuerdo con la procedencia geográfica del paciente, pero predomina en personas afrodescendientes y escandinavas. Las anormalidades torácicas son muy frecuentes en los pacientes con sarcoidosis; la afectación más común es ganglionar y la menos común es la del corazón. Las manifestaciones radiológicas más frecuentes en el compromiso torácico por sarcoidosis son las adenomegalias hiliares y mediastinales, así como nódulos pulmonares de distribución perilinfática.

\section{Summary}

Sarcoidosis is a chronic, multisystemic disease of unclear etiology. The presentation is variable according to the geographical origin of the patient, predominantly in Afro-descendant and Scandinavian patients. Chest abnormalities are very frequent in patients with sarcoidosis, taking into account that the most common involvement is lymphatic and the least common is heart involvement. The most frequent radiological manifestations in thoracic involvement due to sarcoidosis are hilar and mediastinal adenomegalies as well as pulmonary nodules with perilymphatic distribution.

\section{Introducción}

La sarcoidosis es una enfermedad crónica, multisistémica, inflamatoria, de etiología no clara, mayormente observada en mujeres afroamericanas e individuos en la tercera década de la vida (1).

La presentación es variable de acuerdo con la procedencia geográfica del paciente. En Estados Unidos, la incidencia anual en población afroamericana es de 35,5 casos frente a 10,9 en los caucásicos por cada 100.000 habitantes (2). Las poblaciones afroamericanas y escandinavas tienen una mayor frecuencia de sarcoidosis, mientras que es poco común en Asia o América del Sur (3). Se ha encontrado que las personas expuestas a incendios, procesamiento de metales, insecticidas, moho, partículas inorgánicas y productos químicos agrícolas tienen mayor riesgo de contraer sarcoidosis (4).

La patogenia no es del todo clara; sin embargo, se ha encontrado que la activación y reclutamiento de linfocitos T CD4+, la acumulación de macrófagos y el desarrollo de granulomas epitelioides estériles no caseificantes se encuentran involucrados con una alta expresión de interferón- $\gamma$ en la sarcoidosis activa (1). La necrosis es rara en la sarcoidosis, con la excepción de una variante llamada granulomatosis sarcoidea necrotizante (4). Las anormalidades torácicas se evidencian en más del $90 \%$ de los pacientes con sarcoidosis (5), y de estas, la afectación más común es en el mediastino y la menos común es la del corazón, pero con mayores tasas de morbimortalidad en comparación con el compromiso pulmonar $(1,4)$.

Hasta el $50 \%$ de los pacientes son asintomáticos y las anomalías en las imágenes se detectan incidentalmente en la radiografía de tórax realizada por una indicación diferente (1). Los síntomas de la sarcoidosis pulmonar incluyen tos, disnea y dolor torácico. La sarcoidosis pulmonar puede ser difícil de evaluar, porque la sintomatología, los hallazgos radiológicos y los resultados de las pruebas de función pulmonar pueden ser discordantes entre sí (6).

Las manifestaciones radiológicas más frecuentes en el compromiso torácico por sarcoidosis son las adenomegalias hiliares y mediastinales, y nódulos de distribución perilinfática (3); sin embargo, hay presentaciones atípicas de la enfermedad que se deben tener en cuenta para un diagnóstico diferencial acertado. El diagnóstico final de la sarcoidosis pulmonar se establece cuando se encuentran hallazgos clínicos y radiológicos compatibles, respaldado por evidencia histológica de granulomas no caseificantes o mínimamente caseificantes en una distribución linfangítica y una vez que se descartan otras enfermedades con hallazgos similares (7). También se acepta un diagnóstico de alta probabilidad sin confirmación histológica, cuando los hallazgos clínicos y radiológicos compatibles están respaldados 
por una relación BAL CD4/CD8> 3,5 (especificidad 93-96 \% y sensibilidad 53-59 \%) (7).

El propósito de esta revisión es describir la epidemiología, fisiopatología y hallazgos radiológicos típicos y atípicos de la sarcoidosis torácica en radiología convencional, tomografía computarizada y tomografía por emisión de positrones.

\section{Clasificación radiológica de la sarcoidosis en el tórax}

Se han establecido varios sistemas de estadificación radiográfica para sarcoidosis. El más ampliamente utilizado fue desarrollado por Scadding hace más de cinco décadas (1961) $(4,8-10)$ y modificado por DeRemee en $1983(7,8)$ (tabla 1). Esta clasificación está descrita para su uso en radiografía de tórax (RT).

\section{Tabla 1. Clasificación radiológica de la sarcoidosis torácica}

\begin{tabular}{|c|l|c|}
\hline Etapa & \multicolumn{1}{|c|}{ Manifestaciones } & $\begin{array}{c}\text { Frecuencia } \\
\text { (\%) }\end{array}$ \\
\hline O & $\begin{array}{l}\text { Ausencia de anomalías en las radiografías } \\
\text { de tórax. }\end{array}$ & $0-15$ \\
\hline I & $\begin{array}{l}\text { Adenomegalias hiliares bilaterales } \\
\text { que pueden estar acompañadas de } \\
\text { adenomegalia paratraqueal derecha y en } \\
\text { la ventana aortopulmonar. }\end{array}$ & $25-65$ \\
\hline II & $\begin{array}{l}\text { Adenomegalias hiliares bilaterales y } \\
\text { compromiso parenquimatoso pulmonar } \\
\text { con un patrón nodular o reticulonodular } \\
\text { simétrico bilateral con distribución } \\
\text { perihilar predominante, en el lóbulo medio } \\
\text { y lóbulo superior. }\end{array}$ & $25-65$ \\
\hline III & $\begin{array}{l}\text { Compromiso parenquimatoso pulmonar } \\
\text { sin adenomegalias hiliares. }\end{array}$ & $10-15$ \\
\hline IV & $\begin{array}{l}\text { Fibrosis con evidencia de patrón } \\
\text { reticular, bronquiectasias de tracción, } \\
\text { masas que causan distorsión de la } \\
\text { arquitectura o quistes en "panal de } \\
\text { abeja", predominantemente en los lóbulos } \\
\text { superiores. }\end{array}$ & \\
\hline
\end{tabular}

Fuente: Silva et al. (8).

El sistema de estadificación es interesante desde un punto de vista histórico. La distribución de los pacientes según las etapas radiográficas depende en gran medida del origen geográfico o étnico, así como de la fuente de referencia (9). En general, el porcentaje de pacientes diagnosticados en etapa 0 es de 5-15\%, etapa I de $25-65 \%$, etapa II de $20-40 \%$, etapa III de $10-15 \%$ y etapa IV aproximadamente $5 \%$ (9). Cabe mencionar que la sintomatología no está relacionada con la etapa radiográfica de la enfermedad (5), ya que este esquema de clasificación es puramente descriptivo y no es indicativo de actividad de la enfermedad (11). A pesar de la nomenclatura, los pacientes no suelen progresar a través de las etapas descritas en un orden secuencial (12). Es decir, un paciente puede presentarse en etapa III y durante el seguimiento pasar a etapa 0 . Por otro lado, un paciente que inicialmente se presenta con enfermedad en estadio I, puede llegar más tarde con enfermedad parenquimatosa solamente (estadio III). Sin embargo, esta clasificación tiene poca reproducibilidad y concordancia interobserva- dor, lo cual la limita para su uso cotidiano (10). Su utilización se ha restringido, además, porque la tomografía computarizada multidetector (TCMD) es una modalidad más útil para el diagnóstico y seguimiento de la sarcoidosis (5). Esta clasificación puede ser extrapolable para aplicarse en TCMD (figura 1).

El tratamiento se considera para pacientes sintomáticos que tienen hallazgos relevantes (adenomegalias hiliares o mediastinales, enfermedad del parénquima pulmonar, fibrosis pulmonar, arritmias, insuficiencia cardiaca congestiva, muerte súbita, entre otras) en exámenes, como pruebas radiológicas, serológicas, endoscópicas, ecocardiográficas y de función pulmonar (6). Los pacientes asintomáticos con enfermedad en estadio 0 o I a menudo no requieren manejo (6). Los pacientes asintomáticos con enfermedad en estadio II-III, anormalidades funcionales leves y parámetros clínicos estables posiblemente no requieran tratamiento en un principio y podrían ser seguidos por hasta 3 años (6).

El sistema de puntuación radiográfica de la Organización Internacional del Trabajo (OIT), desarrollado originalmente para la neumoconiosis, se ha modificado y aplicado a la sarcoidosis (10). En este sistema, las sombras se clasifican en cuatro subtipos (R: reticulonodular; M: masa; C: confluente; o F: fibrosis), a los que se les asigna una puntuación basada en la extensión y la profusión por separado (10). La clasificación de Muers se deriva del sistema de puntuación radiográfica para la neumoconiosis de la Organización Internacional del Trabajo (OIT) y tiene un mayor acuerdo en comparación con la puntuación Scadding (8).

La TCMD, especialmente la tomografía de tórax de alta resolución (TACAR), es la modalidad de elección para evaluar las características de la sarcoidosis torácica. Esta técnica permite determinar los rasgos característicos en el compromiso pulmonar, ganglionar, pleural y de vía aérea. Además, la TCMD permite la valoración de posibles complicaciones o entidades concomitantes como infección o neoplasia (4).

\section{Manifestaciones en el mediastino}

\subsection{Presentación clásica}

Las adenomegalias mediastinales son frecuentes en pacientes con sarcoidosis, especialmente, en la estación paratraqueal derecha y en la ventana aortopulmonar (4). Una de sus principales características es que las adenomegalias son simétricas y no comprimen las estructuras vasculares adyacentes (4), lo que ayuda a diferenciarlas de otras entidades (por ejemplo, linfoma, metástasis o enfermedades infecciosas como tuberculosis) (13). Más del $85 \%$ de los pacientes con sarcoidosis presentan adenomegalias en algún momento durante el curso de su enfermedad (5). Aproximadamente, el $80 \%$ de los pacientes con adenomegalias tienen enfermedad parenquimatosa y, a su vez, más del $80 \%$ de los pacientes con anomalías pulmonares tienen adenomegalias mediastinales (5).

En todos los métodos de imagen es característico que las adenomegalias sean bilaterales y simétricas $(4,5)$. En radiografía de tórax el compromiso hiliar bilateral es el patrón más característico - hasta en el $95 \%$ de los pacientes - con una distribución típica, denominada "1-2-3", porque involucra los ganglios linfáticos hiliares bilaterales y paratraqueales derechos (5). Estudios adicionales han mostrado que el patrón más común muestra adenomegalias en las estaciones ganglionares de la ventana aortopulmonar, paratraqueales derechos e hiliares bilaterales, patrón que se conoce como el "1-2-3-4" (1). 
En el $75 \%-95 \%$ de los pacientes con sarcoidosis, se encuentran hallazgos de adenomegalias mediastinales e hiliares con compromiso hiliar bilateral en el $67 \%$-75\% de los casos en la TCMD (5) (figura 2 ). Las estaciones ganglionares comúnmente comprometidas son: paratraqueal derecha y peribronquial derecha —al menos $55 \%-70 \%$ de los pacientes-, paratraqueal izquierda, ventana aortopulmonar, subcarinal y paraesofágica — cada uno en aproximadamente el $50 \%$ de los pacientes- $(4,5)$. La TCMD puede mostrar adenomegalias mediastinales en ausencia de adenomegalias hiliares hasta en un $15 \%$ de los pacientes (5).
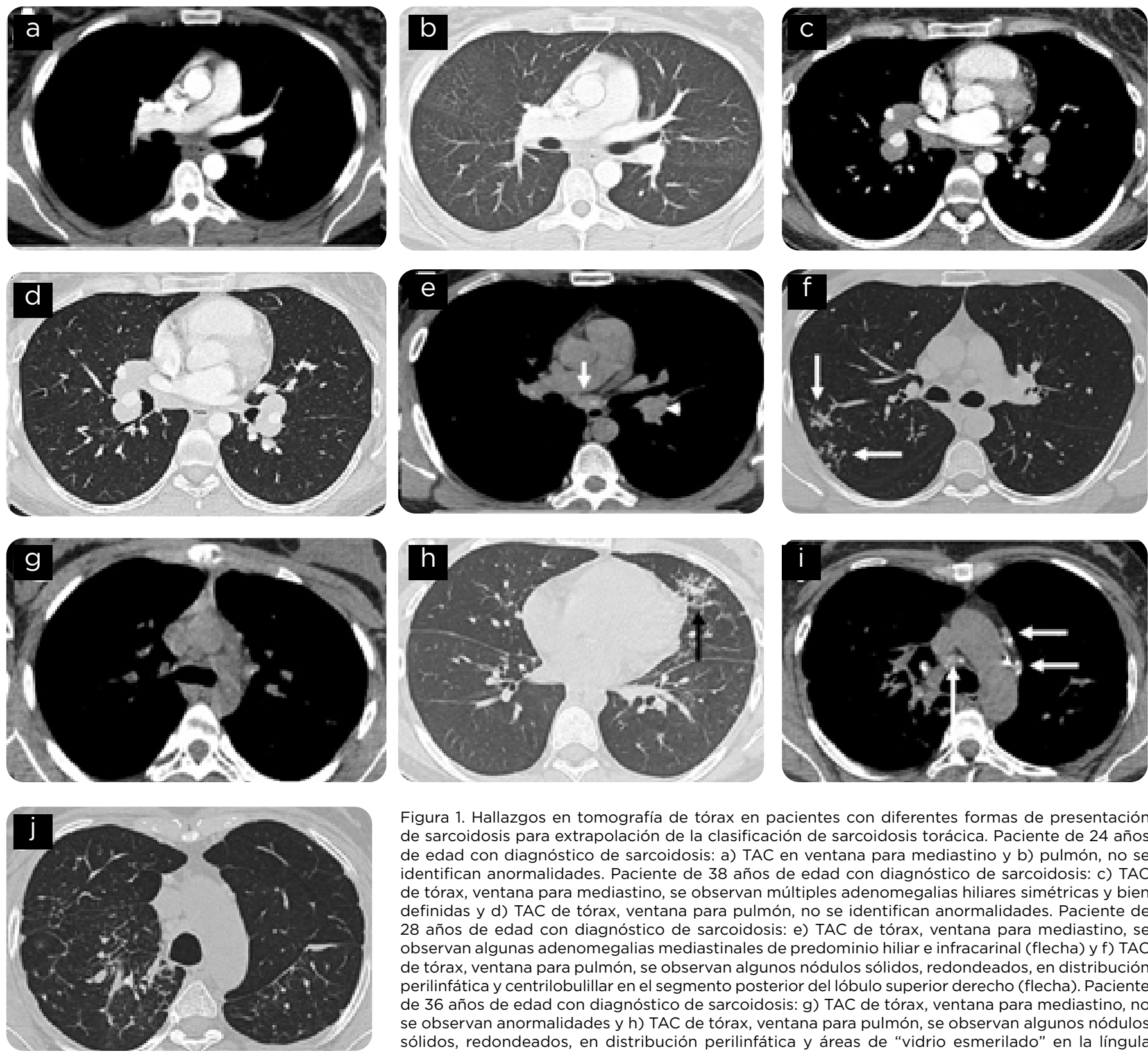

Figura 1. Hallazgos en tomografía de tórax en pacientes con diferentes formas de presentación de sarcoidosis para extrapolación de la clasificación de sarcoidosis torácica. Paciente de 24 años de edad con diagnóstico de sarcoidosis: a) TAC en ventana para mediastino y b) pulmón, no se identifican anormalidades. Paciente de 38 años de edad con diagnóstico de sarcoidosis: c) TAC de tórax, ventana para mediastino, se observan múltiples adenomegalias hiliares simétricas y bien definidas y d) TAC de tórax, ventana para pulmón, no se identifican anormalidades. Paciente de 28 años de edad con diagnóstico de sarcoidosis: e) TAC de tórax, ventana para mediastino, se observan algunas adenomegalias mediastinales de predominio hiliar e infracarinal (flecha) y f) TAC de tórax, ventana para pulmón, se observan algunos nódulos sólidos, redondeados, en distribución perilinfática y centrilobulillar en el segmento posterior del lóbulo superior derecho (flecha). Paciente de 36 años de edad con diagnóstico de sarcoidosis: g) TAC de tórax, ventana para mediastino, no se observan anormalidades y h) TAC de tórax, ventana para pulmón, se observan algunos nódulos sólidos, redondeados, en distribución perilinfática y áreas de "vidrio esmerilado" en la língula (flecha). Paciente de 63 años de edad con diagnóstico de sarcoidosis: i) TAC de tórax, ventana para mediastino, múltiples adenomegalias mediastinales, algunas de ellas calcificadas (flecha) y j) TAC de tórax, ventana para pulmón, se observa alteración de la arquitectura pulmonar con reticulación y nódulos perilinfáticos. 

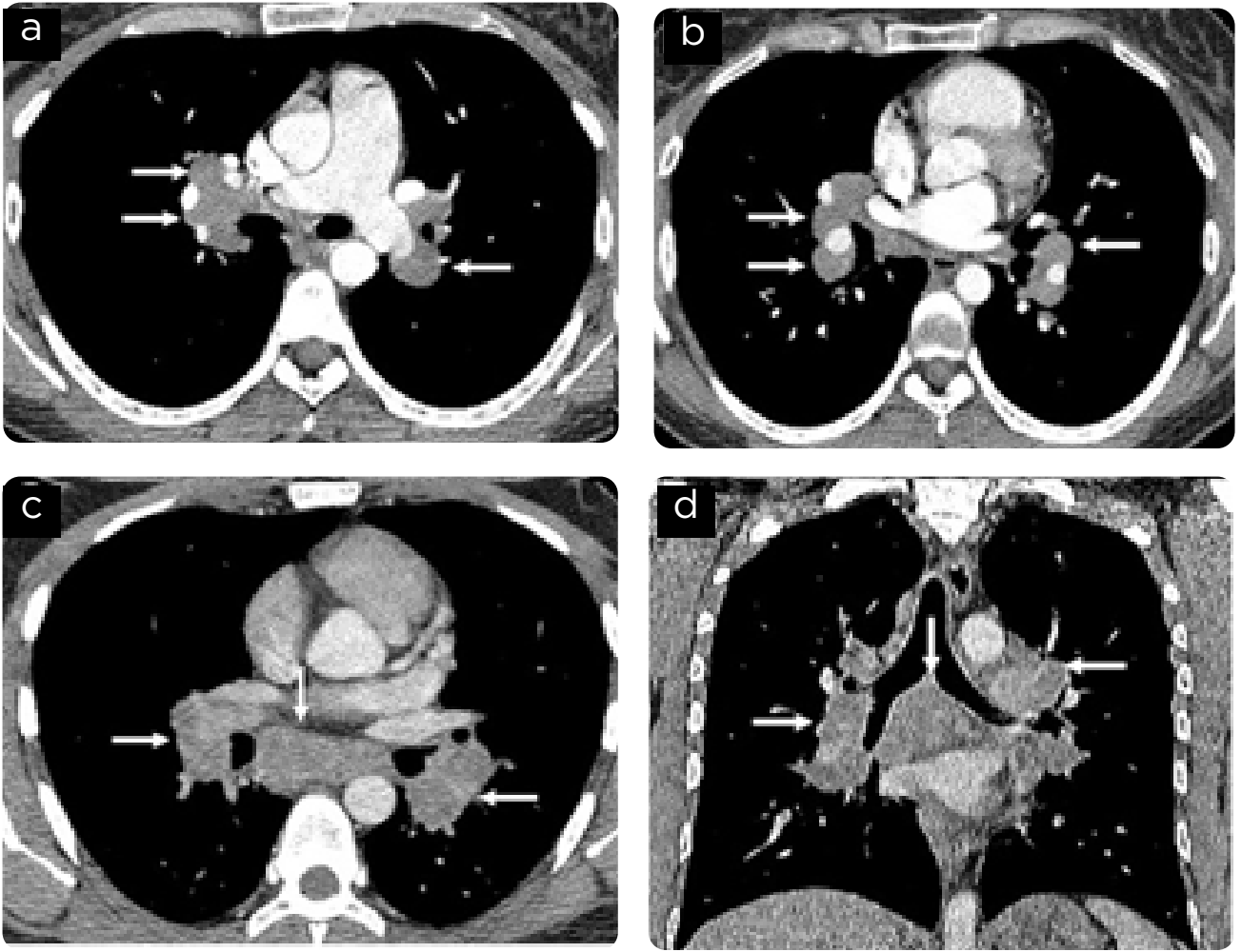

Figura 2. Paciente de 48 años de edad con diagnóstico de sarcoidosis. TAC de tórax con medio de contraste, ventana para mediastino: a) a la altura de la arteria pulmonar y b) en lóbulos inferiores. Múltiples adenomegalias hiliares simétricas y bien definidas que predominan en la región parahiliar (flechas). Paciente de 44 años de edad con diagnóstico de sarcoidosis. TAC de tórax con medio de contraste: c) ventana para mediastino en lóbulos inferiores, d) reconstrucción coronal. Múltiples adenomegalias mediastinales e hiliares simétricas y bien definidas que predominan en la región parahiliar (flechas).
Figura 3. Paciente de 67 años de edad con diagnóstico de sarcoidosis. TAC simple de tórax, ventana para mediastino: a) a la altura del cayado aórtico y b) en la unión gastroesofágica. Se observan adenomegalias mediastinales calcificadas de localización atípica, en la cadena mamaria interna derecha, en $a, y$ adyacente a la unión gastroesofágica, paratraqueales derechas y prevasculares en b. Paciente de 64 años de edad con diagnóstico de sarcoidosis. TAC simple de tórax, ventana para mediastino: c) a la altura de la arteria pulmonar y d) reconstrucción coronal. Se observan múltiples adenomegalias mediastinales $e$ hiliares calcificadas en paciente con antecedente de sarcoidosis de varios años de evolución confirmada mediante biopsia.
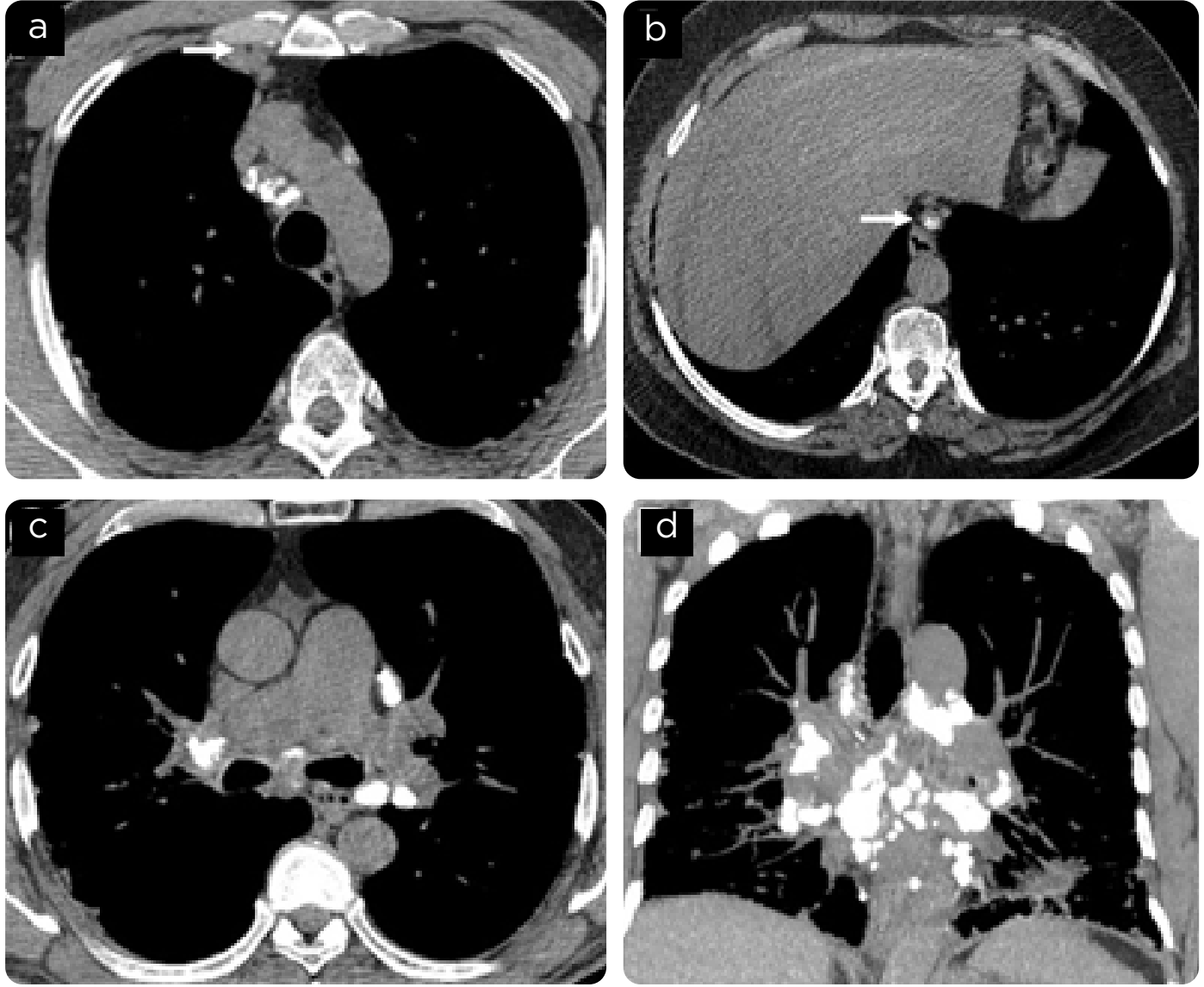


\subsection{Presentación atípica}

La sarcoidosis puede manifestarse como adenomegalias mediastinales o hiliares asimétricas o unilaterales, por lo que se deben tener en cuenta diagnósticos diferenciales, por ejemplo: linfoma, compromiso neoplásico, tuberculosis o, inclusive, otros trastornos granulomatosos (4). Se ha descrito el compromiso unilateral, especialmente derecho, en el $5 \%$ de pacientes (14). Así mismo, localizaciones inusuales - como en las estaciones ganglionares mamarias internas y retrocrurales - se consideran presentaciones atípicas de la enfermedad (figura 3) $(5,14)$.

Es frecuente que las adenomegalias se calcifiquen (figura 3); se pueden encontrar con calcificaciones focales o difusas y con patrones variables: amorfas, punteadas, densas y gruesas, o en "cáscara de huevo" (5), hallazgo que está estrechamente relacionado con la duración de la enfermedad (1). Las calcificaciones focales son más frecuentes que las calcificaciones completas de las adenomegalias (1). Como dato adicional, en resonancia magnética (RM), una adenomegalia de baja señal en las secuencias potenciadas en T1 y T2, denominada "ganglio linfático oscuro", es un signo que se puede encontrar hasta en el $50 \%$ de los pacientes con sarcoidosis (5). Las calcificaciones de las adenomegalias son más frecuentes en pacientes mayores de 50 años $(14,15)$.

\subsection{Complicaciones mediastinales}

La hipertensión pulmonar arterial (HTP) es una complicación ampliamente descrita de la sarcoidosis, denominada hipertensión pulmonar asociada a la sarcoidosis (1), que es independiente de la fibrosis pulmonar $(13,16)$. Ocurre en el $5 \%$ al $74 \%$ de pacientes con sarcoidosis, con una sobrevida a 5 años de aproximadamente $59 \%$. El diagnóstico, al igual que en otras formas de HTP, se hace cuando se encuentra una dilatación de la arteria pulmonar principal que supera los $29 \mathrm{~mm}$ de diámetro transverso (4). Además, es importante obtener el radio entre la arteria pulmonar y la aorta ascendente, que debe ser mayor a 1, para hacer el diagnóstico; además, tiene un valor predictivo de mortalidad independiente de otros factores encontrados en la TCMD (17). Los estudios anatomopatológicos han mostrado una invasión granulomatosa de las paredes de los vasos sanguíneos o fibrosis perivascular, especialmente en vasos venosos, que ocurre en un $69 \%$ al $100 \%$ de pacientes $(18,19)$. Sin embargo, es poco frecuente encontrar cambios de HTP en pacientes con sarcoidosis sin fibrosis pulmonar y secundaria a trombosis o compromiso oclusivo de vasos venosos (20,21). Como se mencionó, su etiología es multifactorial (22) y, por ende, hace parte del grupo 5 de la clasificación de hipertensión pulmonar arterial $(23,24)$.

\section{Manifestaciones en el parénquima pulmonar}

\subsection{Presentación clásica}

El compromiso pulmonar de la sarcoidosis es variado, se caracteriza por nódulos y masas que se encuentran en aproximadamente un $15 \%$ al $25 \%$ de los pacientes (1). La radiografía de tórax muestra compromiso pulmonar por nódulos en aproximadamente $50 \%$ de casos (5). En TCMD, los nódulos son sólidos, bien definidos, tienden a medir entre 2 a $5 \mathrm{~mm}$, su distribución es predominantemente perilinfática ( $75 \%$ a $90 \%$ de casos) $(14,25)$, por lo que se encuentran en los septos interlobulillares, en el intersticio peribroncovascular, las cisuras y las regiones subpleurales con predominio en lóbulos superiores y lóbulo medio (figura 4) (4,26). La distribución de estos nódulos puede ser en "parches", ubicados en zonas de pulmón comprometido entremezclados con zonas de pulmón normal (5). Estos nódulos pueden confluir formando nódulos o masas de mayor tamaño $(27,28)$, simulando áreas de consolidación o una fibrosis masiva progresiva. También se han descrito opacidades perihiliares y peribroncovasculares que se extienden de los hilios pulmonares hacia la periferia con o sin broncograma aéreo, más profusas hacia la zona central, usualmente acompañadas de nódulos (figura 5) $(4,5)$.

La sarcoidosis puede seguir dos caminos: el primero es la regresión espontánea de la enfermedad y sus manifestaciones; el segundo, la progresión de la enfermedad hacia fibrosis pulmonar. La inflamación descontrolada generalmente precede al cambio fibrótico, y hasta el $20 \%$ de los pacientes con sarcoidosis desarrollan fibrosis pulmonar $(14,29,30)$. Los mecanismos de la enfermedad aún no se han entendido completamente, aunque parece estar en juego una interacción compleja de múltiples factores, que incluyen genética, células T CD4 + y citocinas como TNF- $\alpha$. La fibrosis pulmonar corresponde al estadio IV. El desarrollo de fibrosis pulmonar se asocia con una morbilidad significativa y puede ser mortal (31-33) o, inclusive, requerir trasplante pulmonar (34). La disnea, la tos y la hipoxemia son manifestaciones clínicas frecuentes (31). Las pruebas de función pulmonar a menudo muestran restricción de la afectación parenquimatosa, aunque también se reconoce la obstrucción del flujo de aire por fibrosis centrada en las vías respiratorias (31). Cabe resaltar que la fibrosis suele permanecer estable por períodos prolongados, lo que dificulta la evaluación de la actividad de la enfermedad (6). Es importante diferenciar la enfermedad granulomatosa reversible de la fibrosis (cambios irreversibles), ya que el tratamiento de la sarcoidosis se basa en el supuesto de que hay granulomas reversibles $(25,31)$. En este contexto, el PET/CT con 18-Fluorodesoxiglucosa (18-FDG) es útil para evaluar la inflamación activa que indica granuloma reversible (6).

Un patrón reticular persistente en la radiografía de tórax es indicativo de fibrosis. Esta reticulación y fibrosis tienden a ser irregulares, pero predominantes en los lóbulos superiores (1). La progresión de la fibrosis pulmonar produce pérdida de volumen, típicamente de los lóbulos superiores, y retracción en sentido superior del hilio pulmonar que puede ser identificado en radiografía de tórax. Comúnmente se ven las bronquiectasias de tracción y la distorsión arquitectónica. La fibrosis continua puede volverse confluente y dar lugar a tejido fibroso peribroncovascular similar a la masa, simulando la aparición de fibrosis masiva progresiva vista en silicosis (1).

La TCMD es una herramienta útil en la evaluación de pacientes con enfermedad pulmonar por sarcoidosis (figura 6) (25). El hallazgo más común son pseudomasas en lóbulos superiores y medio asociadas con reticulación, alteración de la arquitectura pulmonar y bronquiectasias por tracción con una distribución predominantemente en parches $(6,14)$. Los hallazgos de fibrosis pulmonar en sarcoidosis se diferencian de los patrones de fibrosis pulmonar idiopática, por su distribución y por la uniformidad que presentan los cambios de fibrosis en este último (35-37).

\subsection{Presentación atípica}

Debido a las posibles presentaciones atípicas, la sarcoidosis se ha denominado “el gran simulador”. Por sus características, el diagnóstico 
diferencial puede ser amplio considerando la diseminación linfangítica, la enfermedad pulmonar exposicional, la fibrosis masiva progresiva, la neumonitis por hipersensibilidad y la histiocitosis de células de Langerhans, entre otros $(13,38)$.

Los nódulos al confluir pueden formar una masa (o nódulo de mayor tamaño) rodeada de nódulos en su periferia (nódulos satélites) más pequeños, lo que se ha denominado el signo de "galaxia" $(1,14,39)$, que no es específico de la enfermedad, y se ha descrito en otras entidades granulomatosas y neoplásicas $(1,14)$. Rara vez se encuentran nódulos o masas solitarias en el contexto de un paciente con sarcoidosis (40). Así mismo, múltiples nódulos de mayor tamaño, habitualmente mayores de $5 \mathrm{~mm}$, pueden simular compromiso neoplásico secundario (figuras $7 \mathrm{y}$ 8) (14). Otra forma de presentación descrita es el "cúmulo sarcoideo", el cual representa un grupo de nódulos de predominio periférico que pueden ser de morfología redondeada u ovalada (41).

Las consolidaciones son evidentes en el $10 \%$ al $20 \%$ de pacientes con sarcoidosis (figura 9) (14). Son bilaterales, simétricas y de distribución peribroncovascular con un predominio hacia los lóbulos superiores y medios (14). En estos casos es frecuente encontrar áreas de broncograma aéreo, lo que da una apariencia aún más similar a una consolidación (5).

Las opacidades en "vidrio esmerilado" se pueden encontrar en TCMD hasta en el $40 \%$ de los pacientes (figura 10) $(5,14)$; sin embargo, la frecuencia de este hallazgo en la sarcoidosis es variable (5). La distribución puede ser irregular y rara vez es extensa (14). Estas áreas reflejan la presencia de numerosos granulomas de pequeño tamaño y lesiones fibrosas intersticiales que causan compresión de la vía aérea sin que haya ocupación del alvéolo (14). Las áreas de "vidrio esmerilado" pueden estar en relación con zonas de nodularidad del parénquima pulmonar subyacente (14).

El patrón "miliar" es raro en sarcoidosis y se ha documentado en menos del $1 \%$ de pacientes (14). Cuando se encuentra, en primera instancia es necesario descartar tuberculosis, enfermedad metastásica o, inclusive, enfermedad pulmonar ocupacional (14).

El atrapamiento de aire en la TCMD durante las adquisiciones en espiración también se ve con frecuencia en la sarcoidosis (figura 11) (1). La fibrosis pulmonar puede ocurrir en un $20 \%$ a $25 \%$ de los pacientes con sarcoidosis, que característicamente predomina en los lóbulos superiores y medios (4). En algunas ocasiones, los nódulos confluyen formando masas de mayor tamaño. Se puede desarrollar sobreinfección por aspergilosis pulmonar y formación de micetomas hasta en el $2 \%$ de los pacientes con sarcoidosis, especialmente en quienes cursan con fibrosis pulmonar, enfermedad quística pulmonar, cavitaciones pulmonares preexistentes y bronquiectasias (4).

\section{Manifestaciones de la vía aérea}

\section{1 Árbol traqueobronquial}

$\mathrm{La}$ afectación traqueobronquial también puede ocurrir, aunque con poca frecuencia, y puede plantear un desafío diagnóstico (4). En la vía aérea principal, la TCAR puede mostrar pequeños granulomas en las paredes traqueales o bronquiales, engrosamiento o irregularidad de la pared o bronquiectasias focales $(5,42)$. El compromiso de la tráquea no es común; sin embargo, puede afectar los bronquios segmentarios y subsegmentarios (43). Se han descrito áreas de este- nosis focal de la tráquea que pueden ser secundarias a una compresión extrínseca derivada de adenomegalias en el mediastino (43). De igual manera, en TCMD, se pueden encontrar zonas de estenosis de la vía aérea con apariencia nodular o lisa (figura 12) (43). La disminución del calibre de los bronquios segmentarios puede provocar atelectasias, especialmente en el lóbulo medio derecho (1). Las anomalías bronquiales consisten principalmente en engrosamiento de la pared bronquial nodular o pequeñas lesiones endobronquiales (44).

\subsection{Vía aérea pequeña}

La sarcoidosis puede involucrar las vías aéreas pequeñas. Los granulomas en las vías respiratorias pequeñas pueden dar lugar a atrapamiento de aire y, como consecuencia, mostrar áreas de atenuación en mosaico más evidentes en la TCMD espiratoria. El atrapamiento de aire es común y puede ocurrir en hasta en el $95 \%$ de los pacientes (5).

\section{Manifestaciones pleurales}

Se ha documentado afección pleural entre el $1 \%$ y el $4 \%$ en pacientes con sarcoidosis $(14,45,46)$. Los pacientes pueden desarrollar opacidades pulmonares en forma de placa, de localización subpleural, causadas por agregaciones subpleurales de pequeños nódulos parenquimatosos denominados "pseudoplacas", las cuales tienen márgenes irregulares, pero bien definidos $(5,14)$. También se han descrito opacidades pulmonares que simulan placas pleurales, denominadas "opacidades en forma de placa pleural" (figura 13) (1).

El derrame pleural (hemorrágico o quilotórax) es una complicación muy rara y se presenta en casos de sarcoidosis como manifestación secundaria a la compresión extrínseca de las adenomegalias mediastinales $(14,47)$. El derrame pleural, en caso de encontrarlo, es escaso y suele resolver espontáneamente entre 2 y 3 meses después de su aparición (14). Los derrames generalmente se observan en casos con afección pulmonar o sistémica extensa (44). Los aspirados pleurales linfocíticos, a menudo manchados de sangre, son característicos del compromiso (44). Se puede hacer un diagnóstico cuando las biopsias pleurales muestran granulomas no caseificantes sin bacilos ácido-resistentes por tinción o en condiciones de cultivo (44).

En raras ocasiones se han descrito hallazgos de neumotórax como complicaciones secundarias a la ruptura de bullas subpleurales en pacientes en fases fibróticas de la enfermedad $(14,45)$.

\section{Utilidad del PET/CT en la valoración de la sarcoidosis torácica}

Aunque la tomografía por emisión de positrones (PET-CT) no está incluida en el estudio estándar para la sarcoidosis (8), hay evidencia que respalda el valor de este examen para guiar el diagnóstico y el manejo de estos pacientes. La PET-CT tiene gran utilidad para definir procesos inflamatorios activos (8), sirve además para evaluar granulomas reversibles, la respuesta al tratamiento, la extensión de la enfermedad, la enfermedad oculta, la sarcoidosis ósea o cardiaca, y para determinar el sitio de biopsia más adecuado (6). La utilidad de PET es cada vez mayor en los casos de afectación cardiaca en sarcoidosis, para determinar la actividad del proceso inflamatorio, ya que, aunque clínicamente solo se detecta en aproximadamente el $5 \%$ de 
los pacientes, en diferentes series de autopsias dicho compromiso se ha encontrado hasta en un $25 \%$ de los casos (48). Para determinar la afectación cardiaca se han utilizado en conjunto imágenes de RM y PET, como se recomienda en la declaración del consenso de expertos de la Sociedad del Ritmo Cardiaco de 2014 (49). El 73 \% de los pacientes con sarcoidosis demuestran actividad de la enfermedad en el PET-CT (50). La 18FDG-PET identifica la captación clínicamente silenciosa en el $15 \%$ de los pacientes con sarcoidosis (8) y su uso puede ser una guía para la identificación de zonas de biopsia para diagnóstico en un $3,8 \%$ de pacientes (51). Las adenomegalias mediastinales e hiliares muestran incremento en la captación del radiotrazador (figura 14) (2), encontrando en algunos casos el "signo de lambda $(\lambda)$ ", que está descrito en las imágenes de medicina nuclear como incremento de la actividad metabólica en ganglios mediastinales de localización paratraqueal derecha e hiliar bilateral (52). En el caso del parénquima pulmonar, se ha demostrado detección de afectación pulmonar en pacientes luego de trasplante (53), en los nódulos pulmonares de la enfermedad (figura 15) y en consolidaciones (figura 16). Después del tratamiento se ha observado disminución de la captación del radiotrazador lo cual demuestra su utilidad en el seguimiento de la enfermedad (54). Se debe tener en cuenta que el principal diagnóstico diferencial de la sarcoidosis en PET-CT es la neoplasia (52), anotando que se ha documentado que los pacientes con esta entidad tienen un riesgo 5,5 veces más alto de padecer trastornos linfoproliferativos (2).
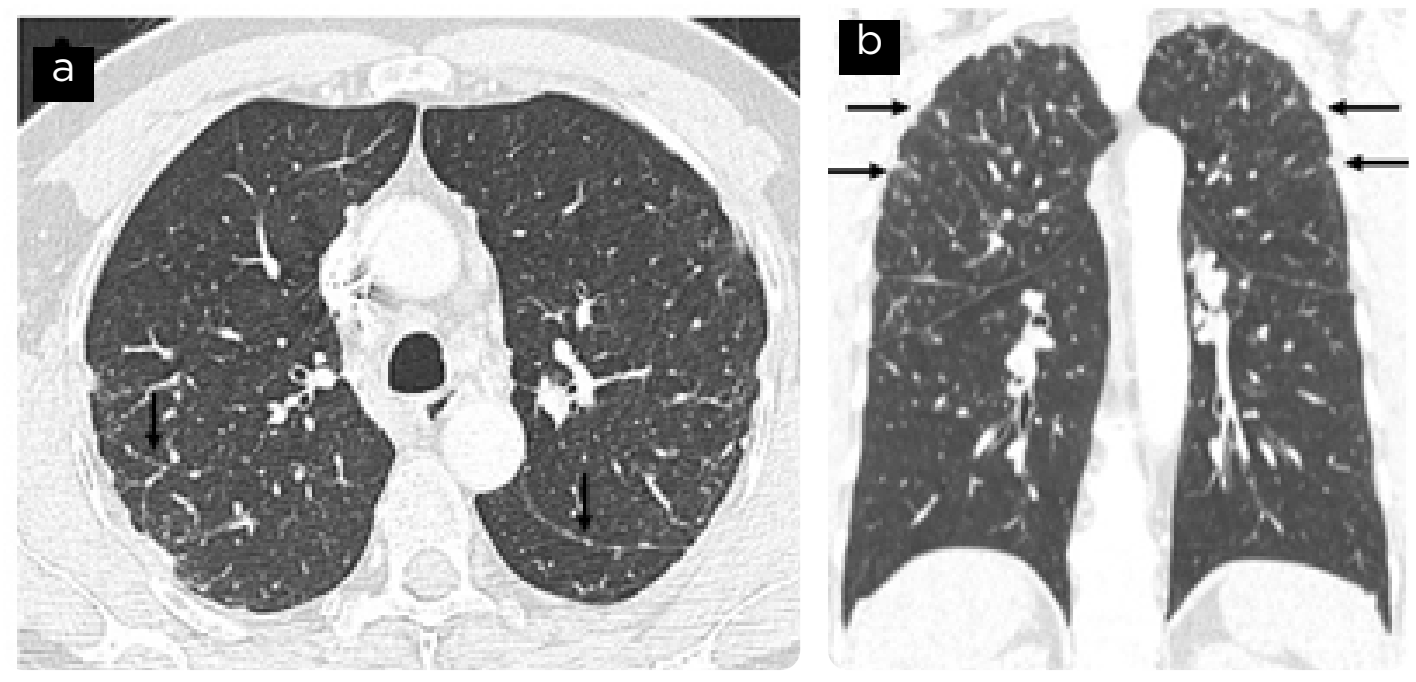

Figura 4. Paciente de 56 años de edad con diagnóstico de sarcoidosis. TAC simple de tórax, a) ventana para pulmón y b) reconstrucción coronal. Se observan nódulos sólidos con densidad de tejidos blandos no mayores de $5 \mathrm{~mm}$ de disposición perilinfática (flechas).
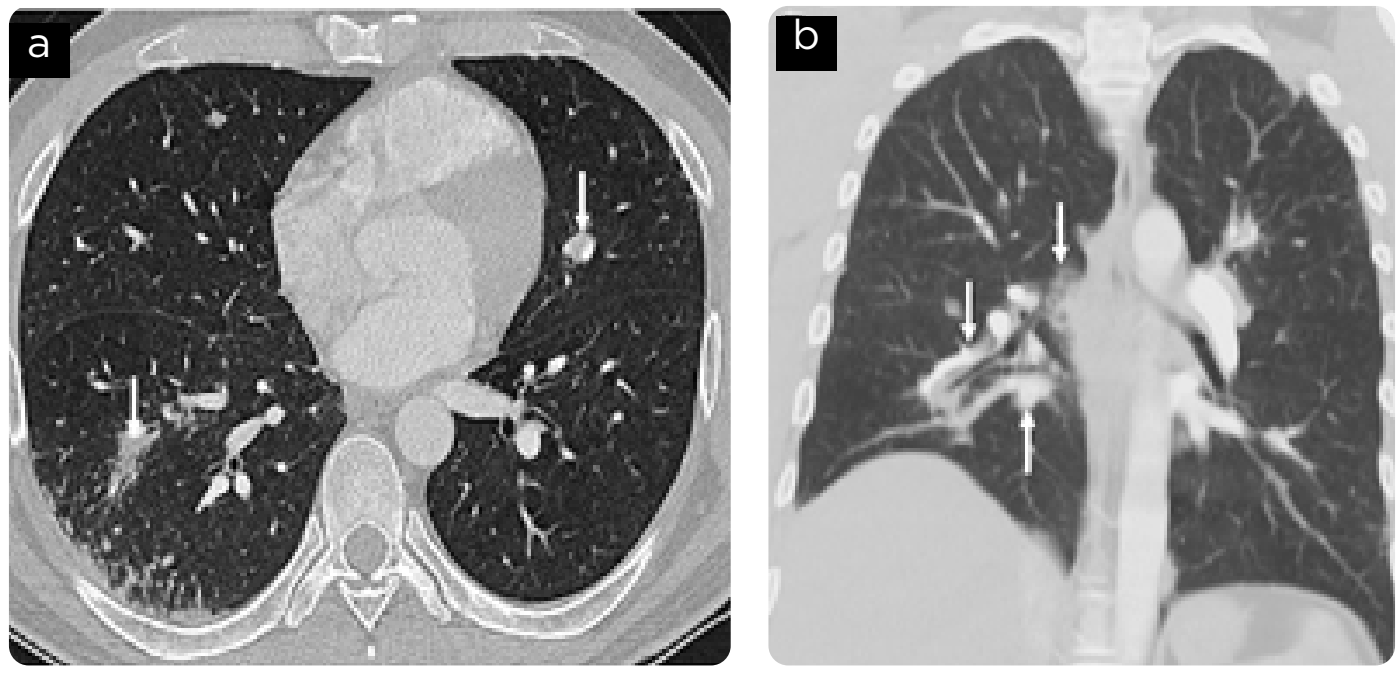

Figura 5. Paciente de 24 años de edad con diagnóstico de sarcoidosis. TAC simple de tórax, ventana para pulmón en a) lóbulos inferiores y b) reconstrucción coronal. Se observan opacidades peribroncovasculares con predominio en el lóbulo inferior derecho. 

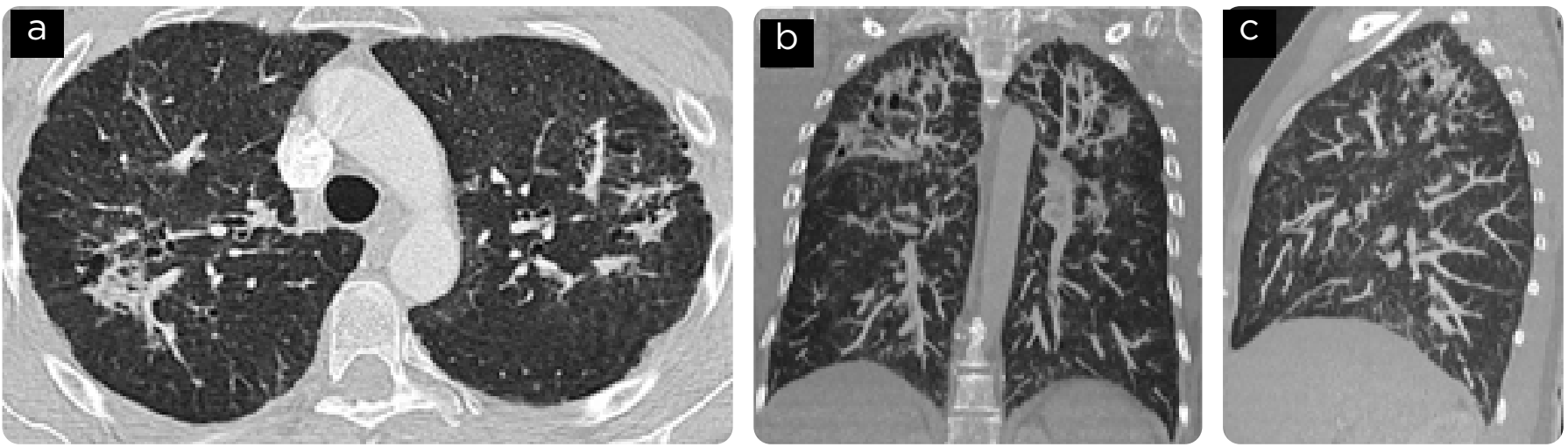

Figura 6. Paciente de 49 años de edad con diagnóstico de sarcoidosis de varios años de evolución. TAC simple de tórax: a) ventana para pulmón en lóbulos superiores, b) reconstrucción coronal y c) sagital. Se observa alteración de la arquitectura pulmonar con engrosamiento irregular de septos interlobulillares, bronquiectasias y áreas de cavitación en los lóbulos superiores por cambios fibróticos.
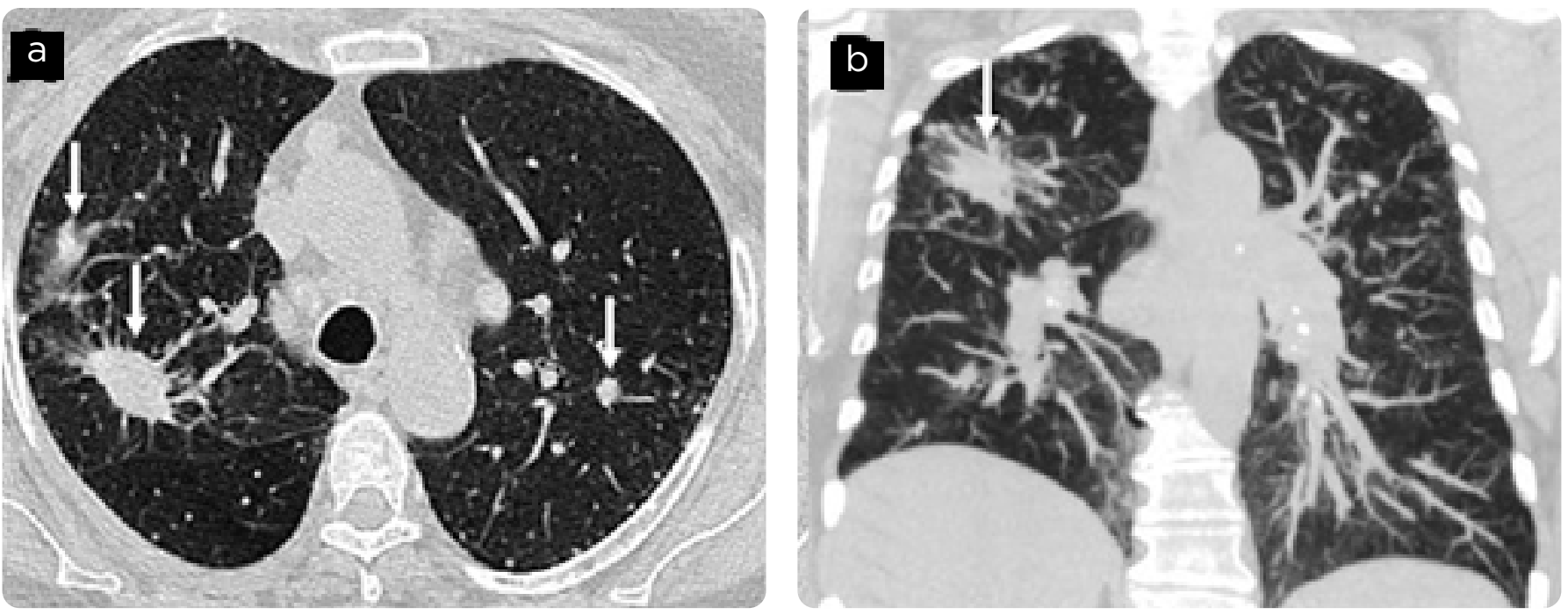

Figura 7. Paciente de 52 años de edad con diagnóstico de sarcoidosis. TAC simple de tórax, a) ventana para pulmón en lóbulos superiores y b) reconstrucción coronal. Se observa nódulo sólido, ovalado, de contornos espiculados en el lóbulo superior derecho (flecha blanca) y algunos nódulos de menor tamaño en lóbulo superior derecho, lóbulo inferior derecho y lóbulo superior izquierdo. Hay demás algunos nódulos perilinfáticos.

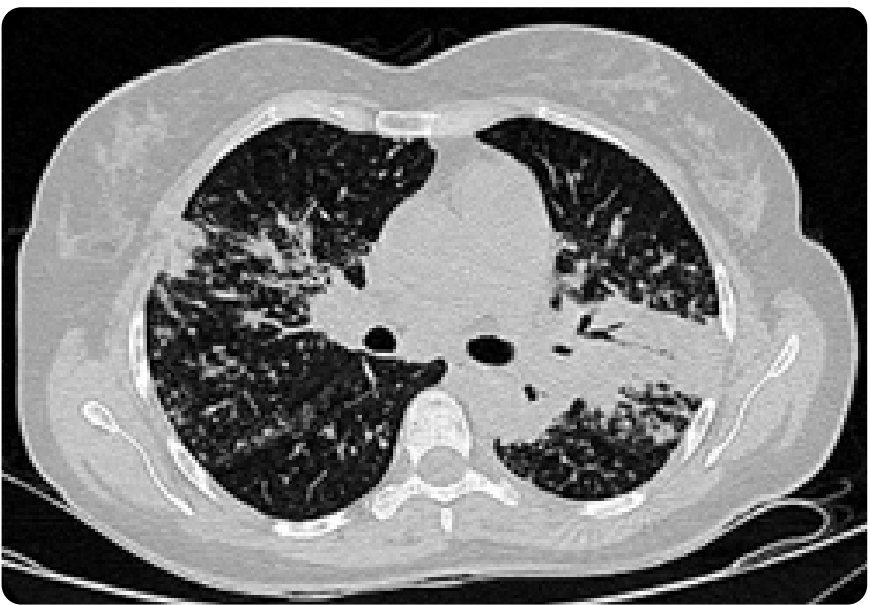

Figura 8. Paciente de 47 años de edad con diagnóstico de sarcoidosis TAC simple de tórax, ventana para pulmón por debajo de la carina. Masas parahiliares bilaterales con calcificaciones en el interior, bilaterales, simétricas, con broncograma aéreo. Hay nódulos de distribución perilinfática asociados.

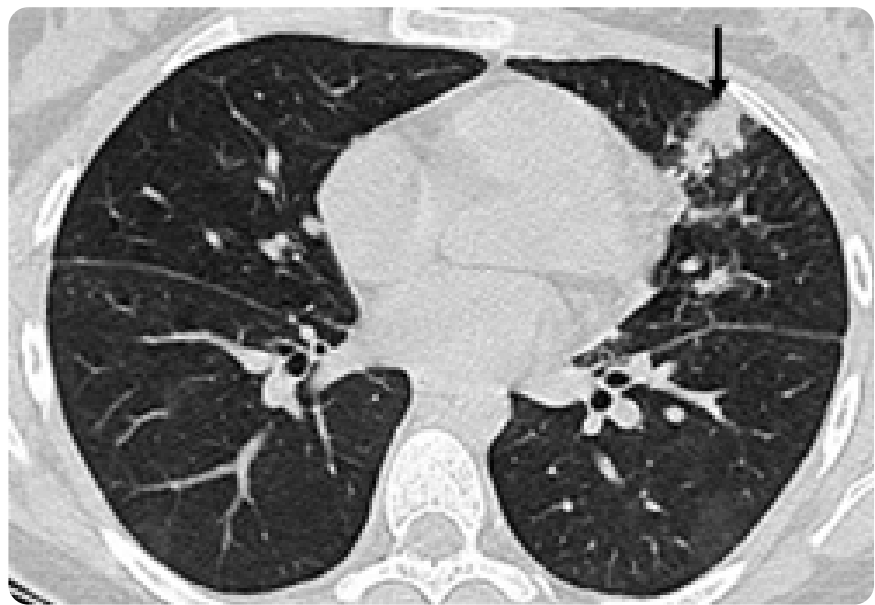

Figura 9. Paciente de 41 años de edad con diagnóstico de sarcoidosis TAC simple de tórax, ventana para pulmón. Área de consolidación en el segmento superior de la língula (flecha). 

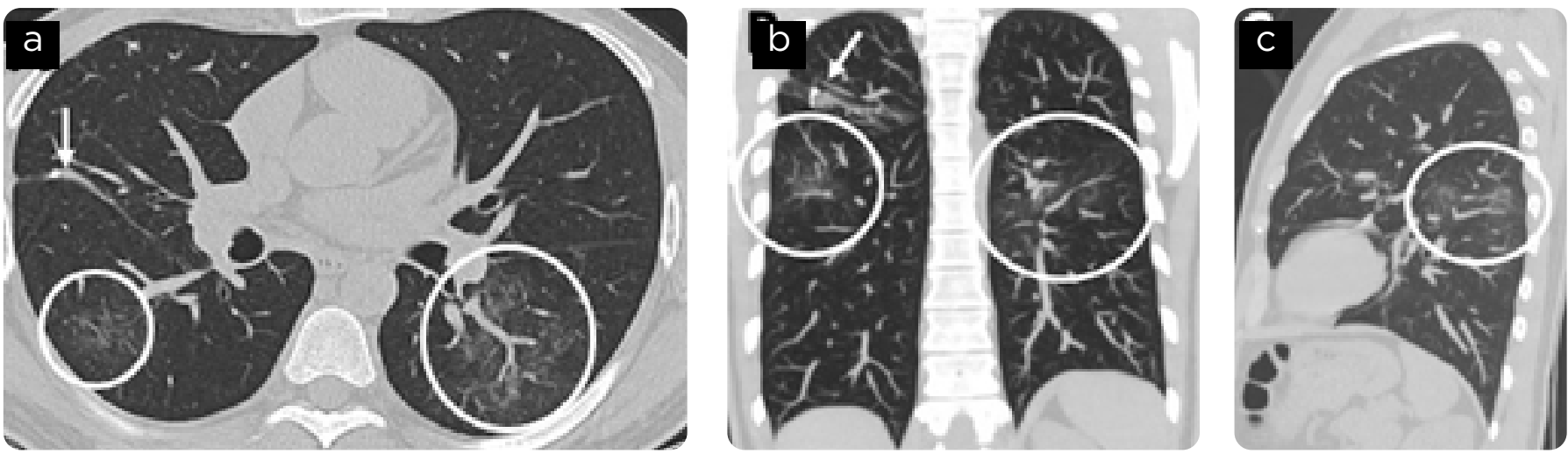

Figura 10. Paciente de 23 años de edad con diagnóstico de sarcoidosis. TAC simple de tórax: a) ventana para pulmón en lóbulos inferiores, b) reconstrucción coronal y c) sagital. Área de "vidrio esmerilado" en el lóbulo inferior izquierdo en paciente con diagnóstico comprobado de sarcoidosis. Sutura metálica en el lóbulo superior derecho y lóbulo medio (flecha).

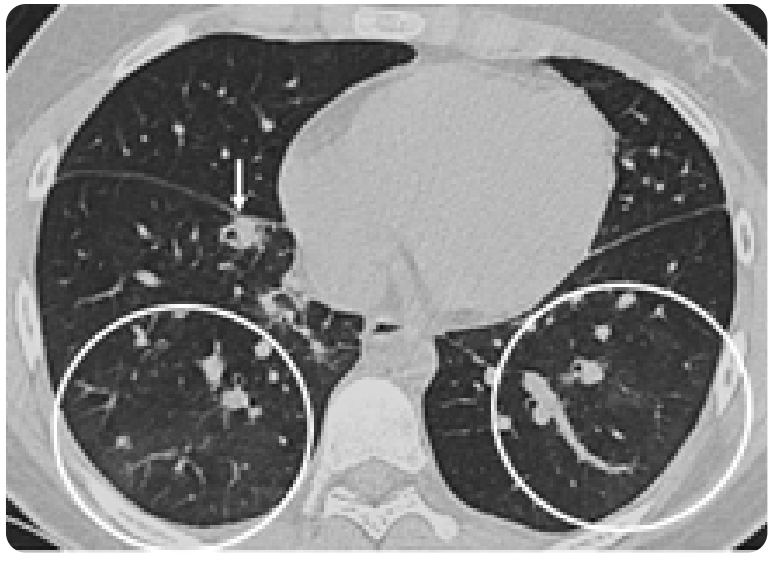

Figura 11. Paciente de 31 años de edad con diagnóstico de sarcoidosis TAC simple de tórax, ventana para pulmón. Discretas áreas de "vidrio esmerilado" de disposición geográfica, de predominio en lóbulos inferiores compatibles con mosaico de atenuación secundario a compromiso de la vía aérea. Hay algunas áreas de consolidación peribroncovascular (flecha blanca).

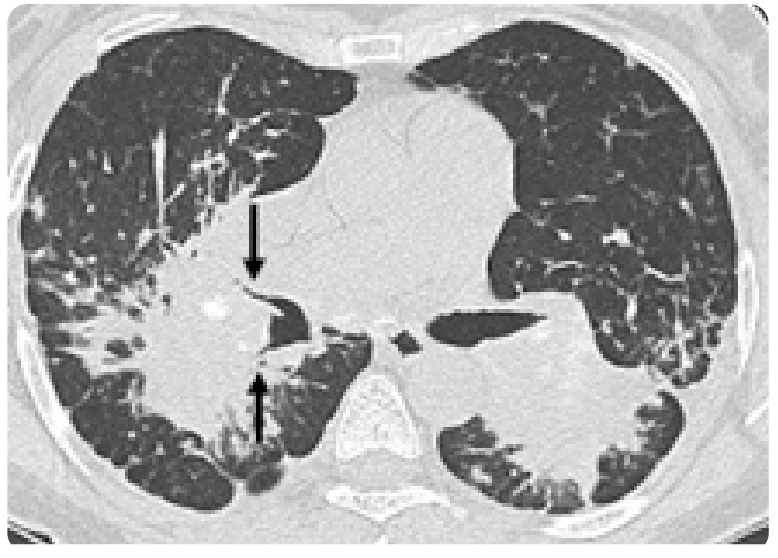

Figura 12. Paciente de 61 años de edad con diagnóstico de sarcoidosis TAC simple de tórax, ventana para pulmón en lóbulos inferiores. Masas parahiliares bilaterales con calcificaciones en el interior, bilaterales, simétricas, asociadas con nódulos de distribución perilinfática. Hay disminución del calibre del bronquio para el lóbulo medio y para el lóbulo inferior derecho (flechas negras), que causan obliteración casi completa del mismo.
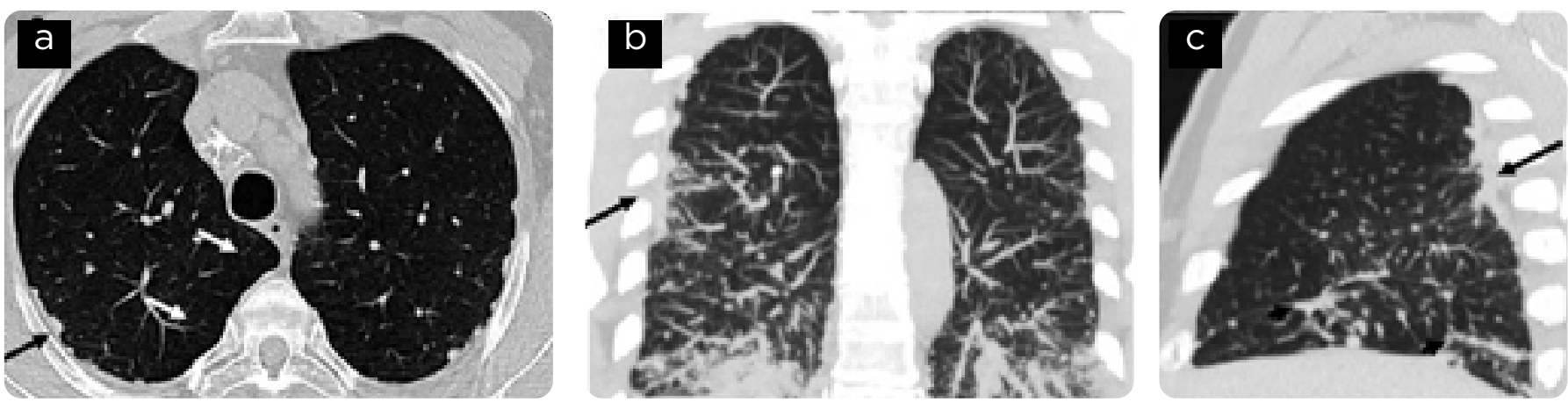

Figura 13. Paciente de 65 años de edad con diagnóstico de sarcoidosis. TAC simple de tórax, ventana para pulmón: a) en lóbulos superiores, b) reconstrucción coronal y c) reconstrucción sagital. Opacidades nodulares subpleurales (flecha blanca) con densidad de tejidos blandos, algunas confluentes configurando placas pleurales (flecha negra). Hay múltiples nódulos sólidos de predominio perilinfático y subpleural en lóbulos inferiores (flecha negra corta en c y d). 

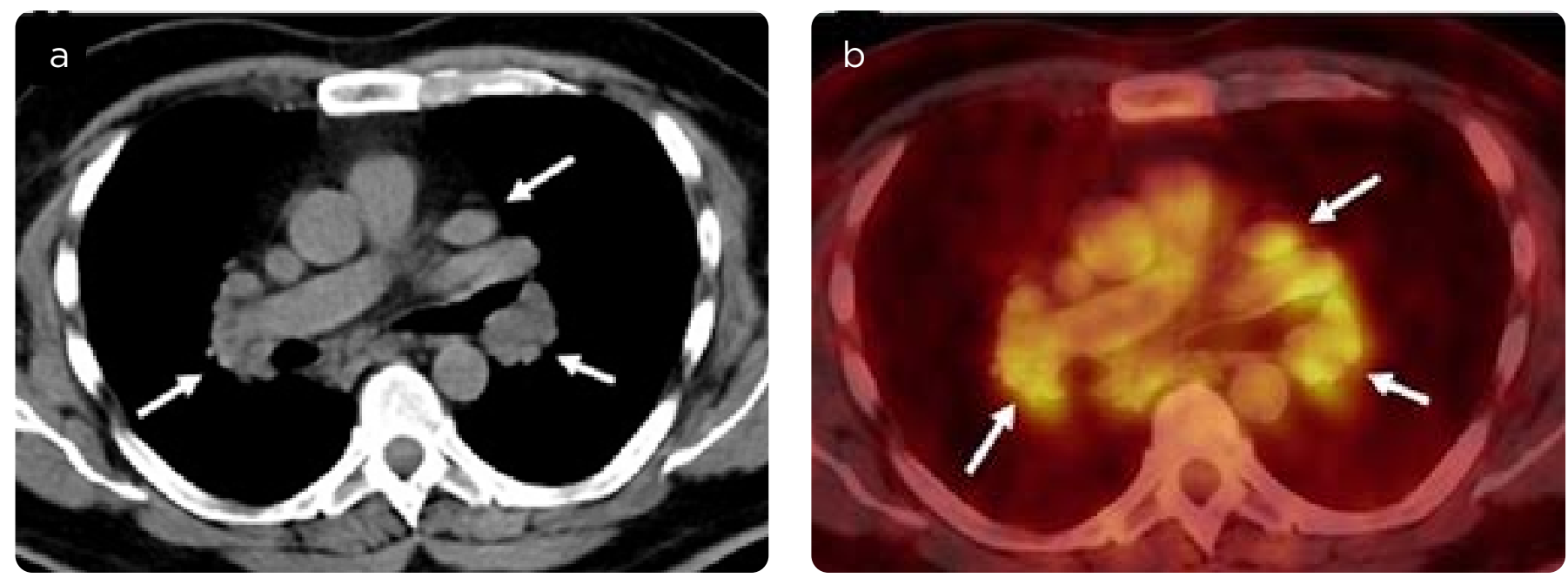

Figura 14. a) Imágenes axiales de TC simple para corrección de atenuación y b) fusión PET-CT. Se identifican adenopatías hiliares bilaterales hipermetabólicas (flechas blancas), en paciente con sarcoidosis activa.
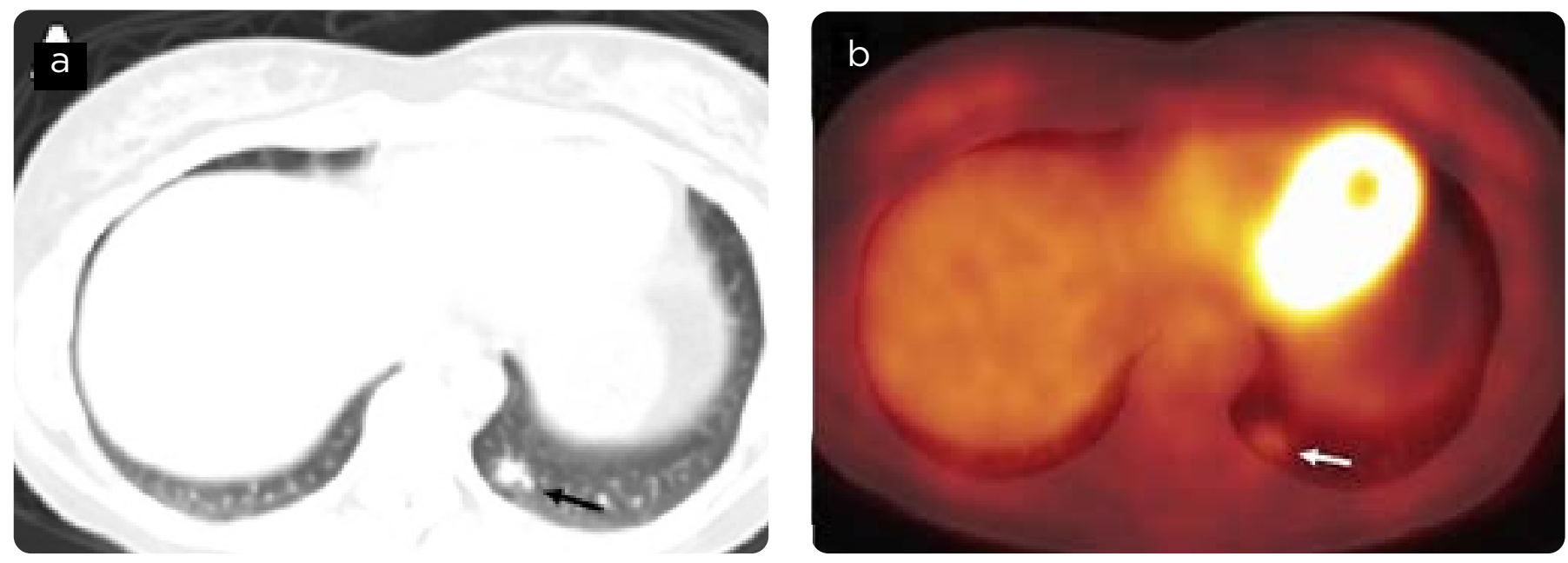

Figura 15. Imágenes axiales de TC simple para: a) corrección de atenuación y b) fusión PET-CT. Paciente de 42 años de edad con antecedente de sarcoidosis: se encuentra nódulo sólido, lobulado y espiculado en el segmento posterior del lóbulo inferior izquierdo (flecha negra), con baja actividad metabólica (flecha blanca). Se realiza seguimiento con TAC de alta resolución, y se observa remisión completa del nódulo a los 6 meses.
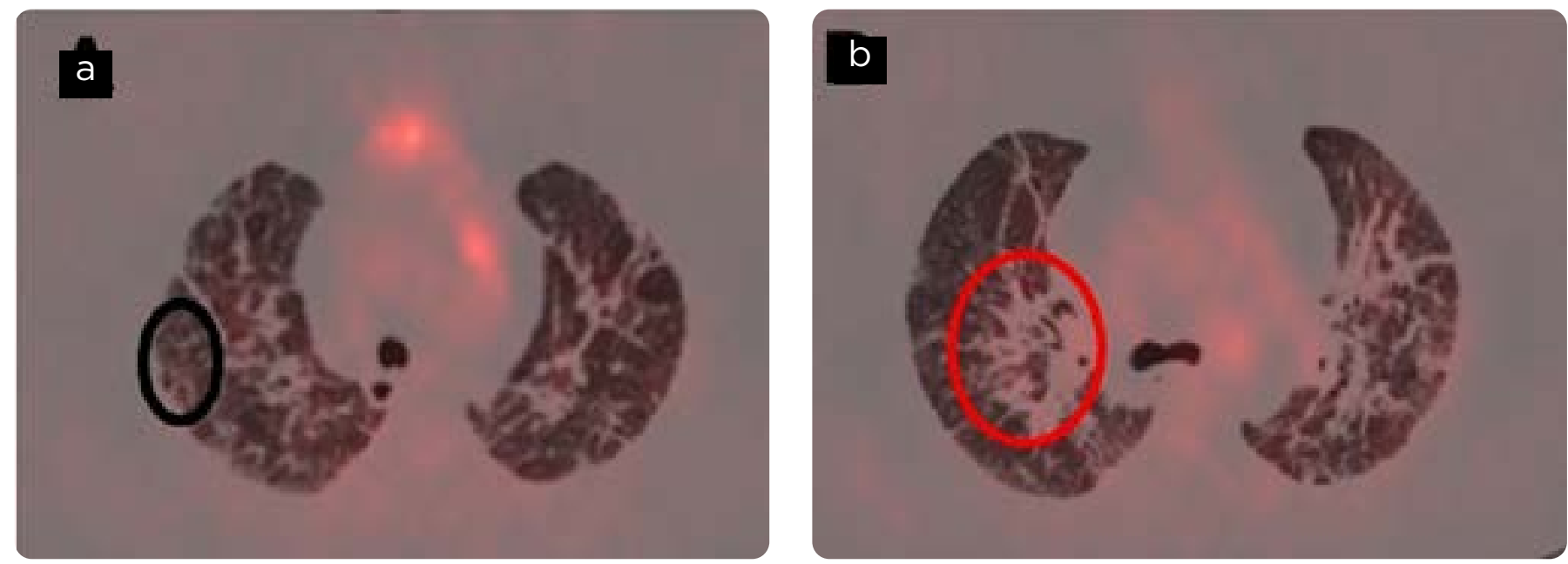

Figura 16. a y b). Imágenes axiales de fusión PET-CT. En los lóbulos superiores se encuentran predominantemente opacidades intersticiales reticulares subpleurales (elipse negra) y engrosamiento intersticial peribroncovascular (elipse roja), en paciente con sarcoidosis tipo IV, con cambios fibróticos pulmonares, sin incremento significativo de la actividad metabólica en el parénquima. (Cortesía de la doctora Gabriela Segura, Hospital de especialidades Carlos Andrade Marín, Quito, Ecuador) 


\section{Conclusiones}

La sarcoidosis es una enfermedad con múltiples manifestaciones sistémica, y el tórax no es la excepción. Las manifestaciones intratorácicas más frecuentes son las adenomegalias hilares y mediastinales bilaterales, además de nódulos pulmonares con distribución perilinfática; sin embargo, hay pacientes con manifestaciones atípicas o incluso un porcentaje menor sin manifestaciones torácicas. Se debe conocer el espectro de hallazgos radiológicos de esta enfermedad en los métodos de imagen más frecuentemente utilizados.

\section{Referencias}

1. Lee GM, Pope K, Meek L, Chung JH, Hobbs SB, Walker CM. Sarcoidosis: A diagnosis of exclusion. AJR. 2020;214:1-9. doi: 10.2214/AJR.19.21436.

2. Prabhakar HB, Rabinowitz CB, Gibbons FK, O’Donnell WJ, Shepard JO, Aquino SL. Imaging features of sarcoidosis on MDCT, FDG PET, and PET/CT. AJR. 2008;190:S1-S6. doi: 10.2214/AJR.07.7001.

3. Semionov A, Kosiuk J, Ajlan AM, Discepola F. Thoracic diseases with musculoskeletal manifestations and vice versa: A review. AJR. 2018;211:1000-9. doi: 10.2214/ AJR.18.19803.

4. Ganeshan D, Menias CO, Lubner MG, Pickhardt PJ, Sandrasegaran K, Bhalla S. Sarcoidosis from head to toe: what the radiologist needs to know. Radiographics. 2018;38(4):1180-200. doi: 10.1148/rg.2018170157.

5. Reddy GP, Ahuja J. Thoracic sarcoidosis: Imaging patterns. Sem Roentgenol. 2019;54(1):59-65. doi: 10.1053/j.ro.2018.12.008.

6. Akaike G, Itani M, Shah H, et al. PET/CT in the diagnosis and workup of sarcoidosis: Focus on atypical manifestations. RadioGraphics. 2018;38:1536-49. doi: 10.1148/ rg.2018180053.

7. Ortega IH, González LL. Update thoracic sarcoidosis. Radiología. 2011;53(5):43448. doi:10.1016/j.rx.2011.03.010.

8. Silva M, Nunes H, Valeyre D, Sverzellati N. Imaging of sarcoidosis. Clinic Rev Allerg Immunol. 2015;49:45-53. doi: 10.1007/s12016-015-8478-7.

9. Nunes H, Brillet PY, Valeyre D, Brauner MW, Wells AU. Imaging in sarcoidosis. Semin Respir Crit Care Med. 2007;28(1):102-20. doi: 10.1055/s-2007-970336.

10. Nunes H, Uzunhan Y, Gille T, Lamberto C, Valeyre D, Brillet PY. Imaging of sarcoidosis of the airways and lung parenchyma and correlation with lung function. Eur Respir J. 2012;40:750-65. doi: 10.1183/09031936.00025212.

11. Spagnolo P, Sverzellati N, Wells AU, Hansell DM. Imaging aspects of the diagnosis of sarcoidosis. Eur Radiol. 2014;24:807-16. doi: 10.1007/s00330-013-3088-3.

12. Keijsers RG, Veltkamp M, Grutters JC. Chest imaging. Clin Chest Med. 2015;36:60319. doi: $10.1016 /$ j.ccm.2015.08.004.

13. Hawtin KE, Roddie ME, Mauri FA, Copley SJ. Pulmonary sarcoidosis: the 'Great Pretender'. Clin Radiol. 2010;65:642-50. doi:10.1016/j.crad.2010.03.004.

14. Criado E, Sánchez M, Ramírez J, Arguis P, de Caralt TM, Perea RJ, et al. Pulmonary sarcoidosis: typical and atypical manifestations at high-resolution CT with pathologic correlation. RadioGraphics. 2010;30:1567-86. doi: 10.1148/rg.306105512.

15. Conant EF, Glickstein MF, Mahar P, Miller WT. Pulmonary sarcoidosis in the older patient: conventional radiographic features. Radiology. 1988;169(2):315-9. doi: 10.1148/radiology.169.2.3174979.

16. Nunes H, Humbert M, Capron F, Brauner M, Sitbon O, Battesti JP, et al. Pulmonary hypertension associated with sarcoidosis: mechanisms, haemodynamics and prognosis. Thorax. 2006;61:68-74. doi: 10.1136/thx.2005.042838.

17. Walsh SL, Wells AU, Sverzellati N, Keir GJ, Calandriello L, AntoniouKM, et al. An integrated clinicoradiological staging system for pulmonary sarcoidosis: a case-cohort study. Lancet Respir Med. 2014;2(2):123-30. doi: 10.1016/S22132600(13)70276-5.

18. Rosen Y, Moon S, Huang CT, Gourin A, Lyons HA. Granulomatous pulmonary angiitis in sarcoidosis. Arch Pathol Lab Med. 1977;101:170-4.

19. Takemura T, Matsui Y, Saiki S, Mikami R. Pulmonary vascular involvement in sarcoidosis: a report of 40 autopsy cases. Hum Pathol. 1992;23:1216-23. doi: 10.1016/0046-8177(92)90288-e.

20. Hoffstein V, Ranganathan N, Mullen JB. Sarcoidosis simulating pulmonary veno-occlusive disease. Am Rev Respir Dis. 1986;134:809-11. doi: 10.1164/ arrd.1986.134.4.809.

21. Jones RM, Dawson A, Jenkins GH, Nicholson AG, Hansell DM, Harrison NK. Sarcoidosis-related pulmonary veno-occlusive disease presenting with recurrent haemoptysis. Eur Respir J. 2009;34:517-20. doi: 10.1183/09031936.00044609.

22. Corte TJ, Wells AU, Nicholson AG, Hansell DM, Wort SJ. Pulmonary hypertension in sarcoidosis: A review. Respirology. 2011;16:69-77. doi: 10.1111/j.14401843.2010.01872.x

23. Simonneau G, Gatzoulis MA, Adatia I, Celermajer D, Denton C, Ghofrani A, et al. Updated clinical classification of pulmonary hypertension. J Am Coll Cardiol. 2013;62(25 suppl):D34-D41. doi: 10.1016/j.jacc.2013.10.029
24. Aluja-Jaramillo F, Gutiérrez FR, Díaz-Telli F, Yevenes-Aravena S, Javidan-Nejad C, Bhalla S. Approach to pulmonary hypertension: From CT to clinical diagnosis Radiographics. 2018;38(2):357-73. doi: 10.1148/rg.2018170046.

25. Koo HJ, Chae EJ, Kim JE, Kim EY, Oh SY, Hwang HJ. Presence of macronodules in thoracic sarcoidosis: prevalence and computed tomographic findings. Clin Radiol. 2015;70(8):815-21. doi: 10.1016/j.crad.2015.03.012.

26. Koyama T, Ueda H, Togashi K, Umeoka S, Kataoka M, Nagai S. Radiologic manifestations of sarcoidosis in various organs. RadioGraphics. 2004;24(1):87-104 doi: 10.1148/rg.241035076.

27. Müller NL, Kullnig P, Miller RR. The CT findings of pulmonary sarcoidosis: analysis of 25 patients. AJR Am J Roentgenol. 1989;152(6):1179-82. doi: 10.2214 ajr.152.6.1179.

28. Hamper UM, Fishman EK, Khouri NF, Johns CJ, Wang KP, Siegelman SS. Typical and atypical CT manifestations of pulmonary sarcoidosis. J Comput Assist Tomogr. 1986;10(6):928-36. doi: 10.1097/00004728-198611000-00006

29. Crystal RG, Roberts WC, Hunninghake GW, Gadek JE, Fulmer JD, Line BR. Pulmonary sarcoidosis: a disease characterized and perpetuated by activated lung T-lymphocytes. Ann Intern Med. 1981;94:73-94. doi: https://doi.org/10.7326/00034819-94-1-73

30. Bonham CA, Strek ME, Patterson KC. From granuloma to fibrosis: sarcoidosis as sociated pulmonary fibrosis. Curr Opin Pulm Med. 2016;22(5):484-91. doi:10.1097 MCP.0000000000000301.

31. Patterson KC, Strek ME. Pulmonary fibrosis in sarcoidosis. Clinical features and outcomes. Annals ATS. 2013;10(4):362-70. doi: 10.1513/AnnalsATS.201303-069FR

32. Gerke AK. Morbidity and mortality in sarcoidosis. Curr Opin Pulm Med. 2014;20(5):472-8. doi: 10.1097/MCP.0000000000000080

33. Viskum K, Vestbo J. Vital prognosis in intrathoracic sarcoidosis with special reference to pulmonary function and radiological stage. Eur Respir J. 1993;6:349-53.

34. Shlobin OA, Nathan SD. Management of end-stage sarcoidosis: pulmonary hypertension and lung transplantation. Eur Respir J. 2012;39(6):1520-33. doi: 10.1183/09031936.00175511

35. Abehsera M, Valerye D, Greiner P, Jaillet H, Battesti JP, Brauner MW. Sarcoidosis with pulmonary fibrosis: CT patterns and correlation with pulmonary function. AJR Am J Roentgenol. 2000;174(6):1751-7. doi: 10.2214/ajr.174.6.1741751.

36. Grenier P, Valeyre D, Cluzel P, Brauner MW, Lenoir S, Chastang C. Chronic diffuse interstitial lung disease: diagnostic value of chest radiography and high-resolution CT. Radiology. 1991;179:123-32. doi: 10.1148/radiology.179.1.2006262.

37. Grenier P, Chevret S, Beigelman C, Brauner MW, Chastang C, Valeyre D. Chronic diffuse infiltrative lung disease: determination of the diagnostic value of clinical data chest radiography, and CT with Bayesian analysis. Radiology. 1994;191: 383-90. doi: 10.1148/radiology.191.2.8153310.

38. Balan A, Hoey ETD, Sheerin F, Lakkaraju A, Chowdhury FU. Multi-technique imaging of sarcoidosis. Clin Radiol. 2010;65:750-60. doi:10.1016/j.crad.2010.03.014

39. Nakatsu M, Hatabu H, Morikawa K, Uematsu H, Ohno Y, Nishimura K, et al. Large coalescent parenchymal nodules in pulmonary sarcoidosis: "sarcoid galaxy" sign. AJR Am J Roentgenol. 2002;178(6):1389-93. doi: 10.2214/ajr.178.6.1781389.

40. Gotway MB, Tchao NK, Leung JW, Hanks DK, Thomas AN. Sarcoidosis presenting as an enlarging solitary pulmonary nodule. J Thorac Imaging. 2001;16(2):117-22. doi: 10.1097/00005382-200104000-00010.

41. Herráez Ortega I, Alonso Orcajo N, López González L. The "sarcoid cluster sign". a new sign in high resolution chest CT [in Spanish]. Radiología. 2009;51(5):495-9. doi: 10.1016/j.rx.2009.05.003.

42. Polychronopoulos VS, Prakash UBS. Airway involvement in sarcoidosis. Chest. 2009; 136:1371-80. doi: 10.1378/chest.08-2569.

43. Aluja-Jaramillo F, Gutiérrez FR, Rossi S, Bhalla S. Nonneoplastic tracheal abnormalities on CT. Contempor Diagn Radiol. 2020:43;13:1-7. doi: 10.1097/01. CDR.0000668640.54833.06

44. Park HJ, Jung JI, Chung MH, Song SW, Kim HL, Baik JH, et al. Typical and Atypical Manifestations of Intrathoracic Sarcoidosis. Korean J Radiol.2009;10:623-631. doi:10.3348/kjr.2009.10.6.623.

45. Soskel NT, Sharma OP. Pleural involvement in sarcoidosis: case presentation and detailed review of the literature. Semin Respir Med. 1992;13(6):492-514.

46. Lynch JP III, Kazerooni EA, Gay SE. Pulmonary sarcoidosis. Clin Chest Med. 1997;18(4):755-85. doi: 10.1016/s0272-5231(05)70417-2.

47. Jarman PR, Whyte MK, Sabroe I, Hughes JM. Sarcoidosis presenting with chylothorax. Thorax. 1995;50(12):1324-5. doi: 10.1136/thx.50.12.1324

48. Blankstein R, Waller AH. Evaluation of known or suspected cardiac sarcoidosis. Circ Cardiovasc Imaging. 2016;9:e000867. doi: 10.1161/CIRCIMAGING.113.000867

49. Birnie DH, Sauer WH, Bogun F, Cooper JM, Culver DA, Duvernoy S, et al. HRS expert consensus statement on the diagnosis and management of arrhythmias associated with cardiac sarcoidosis. Heart Rhythm. 2014;11:1305-23. doi: 10.1016/j. hrthm.2014.03.043.

50. Sobic-Saranovic D, Artiko V, Obradovic V. FDG PET imaging in sarcoidosis. Semin Nucl Med. 2013;43(6):404-11. doi: 10.1053/j.semnuclmed.2013.06.007.

51. Teirstein AS, Machac J, Almeida O, Lu P, Padilla ML, Iannuzzi MC. Results of 188 whole-body fluorodeoxyglucose positron emission tomography scans in 137 patients with sarcoidosis. Chest. 2007;132:1949-53. 
52. Krüger S, Buck AK, Mottaghy FM, Pauls S, Schelzig H, Hombach V, et al. Use of integrated FDG-PET/CT in sarcoidosis. Clin Imaging. 2008;32(4):269-73. doi:10.1016/j.clinimag.2007.11.005

53. Love C, Tomas MB, Tronco GG, Palestro CJ. FDG PET of infection and inflammation. RadioGraphics. 2005;25:1357-68. doi: 10.1148/rg.255045122.

54. Braun JJ, Kessler R, Constantinesco A, Imperiale A. 18F-FDG PET/CT in sarcoidosis management: review and report of 20 cases. Eur J Nucl Med Mol Imaging. 2008;35:1537-43. doi 10.1007/s00259-008-0770-9

\section{Correspondencia}

Felipe Aluja-Jaramillo

Departamento de Radiología

Hospital Universitario San Ignacio

Carrera 7 \# 40-62

falujaj@husi.org.co

Recibido para evaluación: 19 de agosto de 2020

Aceptado para publicación: 14 de diciembre de 2020 